\title{
THE BLOOD FLOW AND OXYGEN CONSUMPTION OF THE HUMAN BRAIN IN DIABETIC ACIDOSIS AND COMA ${ }^{1}$
}

\author{
By SEYMOUR S. KETY, B. DAVID POLIS, CARL S. NADLER, \\ AND CARL F. SCHMIDT

\begin{abstract}
(From the Department of Pharmacology, University of Pennsylvania, and the Metabolic Service, Philadelphia General Hospital, Philadelphia)
\end{abstract}

(Received for publication December 4, 1947)

Despite recent gratifying advances in our knowledge of carbohydrate metabolism, diabetic coma remains an important medical emergency and our understanding of its fundamental pathogenesis and rational treatment is far from complete. The sequence of events leading from disturbed carbohydrate utilization through acidosis, coma and death has been variously defined and important roles have been assigned at one time or another to ketosis, acidosis, dehydration, circulatory failure, and cerebral anoxia.

In an effort better to define these fundamental derangements and their inter-relationships, the brain was chosen as an important object of study since its integrity is so intimately associated with survival. Clinicians who have studied diabetic acidosis are agreed that cerebral function as reflected in mental state is closely correlated with the severity of the disease and its prognosis $(1-6)$. The central nervous system, apparently dependent on carbohydrate for its normal source of energy ( 7 to 9 ), would be expected significantly to reflect disturbances in the metabolism of this foodstuff. For many reasons recently recapitulated by Soskin and Levine (10), the results of extensive in vitro studies may not rigorously be applied to the metabolism of tissues in the living organism so that inferences drawn from work with the Warburg apparatus require validation by studies on living organs in situ. Such studies are comparatively rare because suitable methods have been developed only in the past few years.

The recently devised nitrous oxide method for the quantitative measurement of cerebral blood flow in man $(11,12)$ makes possible calculation of the utilization or production by the brain of any

\footnotetext{
1 This work was supported by grants from the Committee on Research in Dementia Precox, founded by the Supreme Council, $33^{\circ}$ Scottish Rite, Northern Masonic Jurisdiction, U. S. A., and from the Life Insurance Medical Research Fund.
}

substance susceptible of accurate analysis in arterial and cerebral venous blood. In applying this method to diabetic acidosis it was decided first to obtain an overall estimate of cerebral metabolism by determination of the oxygen consumption of the brain and, if possible, an indication of the factors which may influence it in this condition. If this approach appeared feasible, it was hoped that analytical techniques could be refined or developed to permit examination of more specific phases of cerebral metabolism and the aberrations associated with diabetic acidosis. The present report concerns itself largely, therefore, with cerebral oxygen utilization.

\section{METHODS}

Members of the investigating team were notified as soon as a diagnosis of diabetic coma or severe acidosis was made in the receiving ward and confirmed by blood sugar and $\mathrm{CO}_{2}$ determinations. Studies were not attempted where too great a delay in treatment would have resulted, where the acidosis was not very severe, or if the patient was moribund. There was no difference between the mortalities in this series and in comparable patients on the same services before this investigation was undertaken.

Respiratory minute volume was measured in a Tissot spirometer attached to a well-fitted face mask equipped with expiratory and inspiratory valves. Mean arterial blood pressure was read from a damped mercury manometer communicating with a needle in the femoral artery. The nitrous oxide method (12) employing a gas mixture of $15 \% \mathrm{~N}_{2} \mathrm{O}, 21 \% \mathrm{O}_{2}, 64 \% \mathrm{~N}_{2}$, was used for measuring cerebral blood flow.

Blood samples were analyzed for oxygen and carbon dioxide (13), hemoglobin (14), glucose (15), total ketones (16), protein (17), chlorides (18), total base (19) and urea nitrogen (20). Hydrogen ion concentration was measured potentiometrically at $37^{\circ}$ under anaerobic conditions using a glass electrode. Values for $\mathrm{CO}_{2}$ tension were calculated from $\mathrm{CO}_{2}$ content and $\mathrm{pH}$ by means of nomograms (13).

Immediately after the required blood samples were taken, treatment was begun. In seven instances the studies above were repeated at some time (varying from two to 48 hours) after the initiation of treatment. 
RESULTS

Table I contains the pertinent clinical data on the 14 patients on whom practically complete studies were performed, while the biochemical and physiological data are presented in Tables II and III.

Patients. These were fairly evenly distributed with respect to sex and varied in age from 22 to 67. The gaps in the anamnesis result from the fact that many of these patients were unknown or neglected diabetics brought to the hospital in coma with no history obtainable.

Mortality. The mortality for the series of 14 patients was $43 \%$. This figure which appears quite high is completely in line with mortality figures reported for similar patients in this hospital (1) and elsewhere (3 to 5). It agrees well with a predicted mortality of $38 \%$ calculated for this series according to the formula devised by Collen (5). After a little experience with such cases it becomes obvious that there are really two fairly distinct clinical entities involved. One group, which we have classified as severe diabetic acidosis, is tolerating drastic biochemical derangements in homeostasis which have not yet seriously involved the brain and other vital organs. These patients are conscious, though often confused, and suffer little circulatory embarrassment. Their response to insulin and parenteral fluids is gratifying and the mortality is comparatively low $(13 \%$ in our series, $24 \%$ in this hospital for the four years preceding this investigation, $14-28 \%$ in the reports of others who dealt with similar patients

TABLE I

Clinical data

\begin{tabular}{|c|c|c|c|c|c|c|c|}
\hline Patient & Age & Sex & $\begin{array}{l}\text { Usual daily } \\
\text { dose of } \\
\text { insulin }\end{array}$ & $\begin{array}{l}\text { Duration of } \\
\text { drowsiness }\end{array}$ & $\begin{array}{c}\text { Duration of } \\
\text { vomiting }\end{array}$ & Complications & Outcome \\
\hline & yrs. & & units & hrs. & hrs. & & \\
\hline \multicolumn{8}{|c|}{ Severe diabetic acidosis admission data } \\
\hline
\end{tabular}

Diabetic coma admission data

\begin{tabular}{|c|c|c|c|c|c|c|c|}
\hline $\begin{array}{l}\text { M. B. } \\
\text { ?. B. } \\
\text { F. A. } \\
\text { A. D. } \\
\text { F. R. } \\
\text { M. O. }\end{array}$ & $\begin{array}{l}41 \\
60 ? \\
32 \\
38 \\
54 \\
22\end{array}$ & $\begin{array}{l}\mathbf{M} \\
\mathbf{M} \\
\mathbf{M} \\
\mathbf{F} \\
\mathbf{F} \\
\mathbf{F}\end{array}$ & $\begin{array}{l}30 \\
90\end{array}$ & $\begin{array}{c}\text { (coma) } 24 \\
96 \\
96 \\
48\end{array}$ & 30 & $\begin{array}{l}\text { Hepatic cirrhosis } \\
\text { Acute pancreatitis } \\
\text { Erysipelas } \\
\text { Dental abscess }\end{array}$ & $\begin{array}{l}\text { Died } \\
\text { Died } \\
\text { Died } \\
\text { Died } \\
\text { Died } \\
\text { Recovered }\end{array}$ \\
\hline Mean & 41 & & & & & . & . \\
\hline
\end{tabular}

Treatment received between cerebral blood flow studies

\begin{tabular}{|c|c|c|c|c|c|c|c|c|c|}
\hline Patient & $\begin{array}{c}\text { Elapsed time } \\
\text { between } \\
\text { studies }\end{array}$ & $\begin{array}{c}\text { Plasma } \\
\text { liters }\end{array}$ & Phy & aline & Sodiu & onate & $\underset{\text { units }}{\text { Insulin }}$ & $\begin{array}{c}\text { Glucose } \\
\text { gm. }\end{array}$ & $\begin{array}{l}\text { Water } \\
\text { liters }\end{array}$ \\
\hline $\begin{array}{l}\text { J. S. } \\
\text { M. M. } \\
\text { T. H. } \\
\text { C. B. } \\
\text { C. C. } \\
\text { ?. B. } \\
\text { A. D. }\end{array}$ & $\begin{array}{r}\text { hrs. } \\
2 \\
5 \\
15 \\
48 \\
3 \\
2 \\
2\end{array}$ & $\begin{array}{l}I . V . \\
\\
0.5 \\
1.5 \\
1.5\end{array}$ & $\begin{array}{l}I . V . \\
0.7 \\
1.4 \\
1 \\
\\
2\end{array}$ & $\begin{array}{c}S . C . \\
2 \\
2 \\
2 \\
\\
1\end{array}$ & $\begin{array}{c}P . O . \\
14 \\
10 \\
16 \\
12\end{array}$ & $\begin{array}{l}I . V . \\
10 \\
11 \\
11 \\
19 \\
15\end{array}$ & $\begin{array}{l}150 \\
450 \\
500 \\
400 \\
200 \\
300 \\
500\end{array}$ & $\begin{array}{c}I . V . \\
50 \\
50 \\
50 \\
50\end{array}$ & $\begin{array}{l}I . V . \\
1 \\
1 \\
1 \\
0.8 \\
1\end{array}$ \\
\hline
\end{tabular}




\begin{tabular}{|c|c|}
\hline 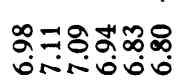 & هั \\
\hline 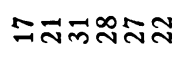 & $\ddot{N}$ \\
\hline 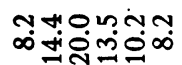 & 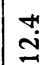 \\
\hline 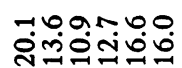 & : \\
\hline กี สกสి & $\stackrel{\infty}{\sim}$ \\
\hline 푸궁요 & $\mid \begin{array}{l}\infty \\
0 \\
0\end{array}$ \\
\hline 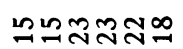 & 9 \\
\hline 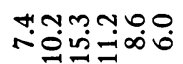 & $\infty$ \\
\hline 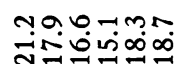 & $\underset{\infty}{0}$ \\
\hline 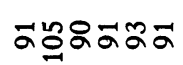 & a゙ \\
\hline 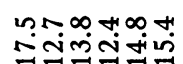 & $\stackrel{+}{+}$ \\
\hline 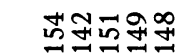 & ga \\
\hline 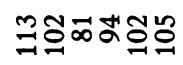 & 8 \\
\hline 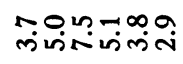 & Fi \\
\hline 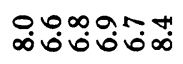 & $\stackrel{m}{?}$ \\
\hline 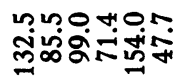 & $\underset{\infty}{\infty}$ \\
\hline 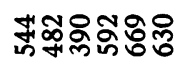 & in \\
\hline 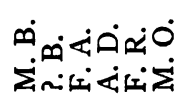 & 节 \\
\hline
\end{tabular}

\begin{tabular}{|c|c|}
\hline 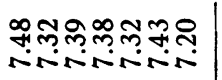 & $\stackrel{+}{\stackrel{m}{n}}$ \\
\hline 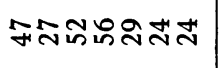 & $\overrightarrow{\text { in }}$ \\
\hline 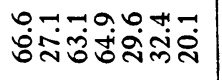 & $\stackrel{0}{i n}$ \\
\hline 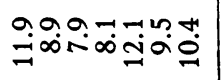 & $\stackrel{\circ}{\Xi}$ \\
\hline$\stackrel{\infty}{\sim}$ & 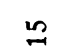 \\
\hline 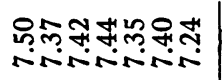 & $\underset{9}{9}$ \\
\hline 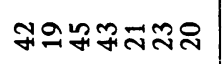 & P \\
\hline 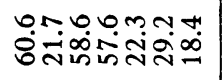 & $\stackrel{9}{\dot{q}}$ \\
\hline 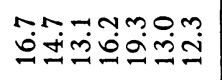 & $\stackrel{\circ}{\stackrel{\infty}{\infty}}$ \\
\hline 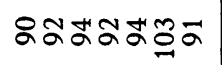 & 2 \\
\hline 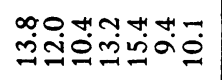 & $\stackrel{\circ}{\dot{I}}$ \\
\hline 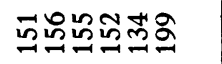 & 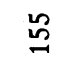 \\
\hline 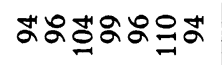 & 8 \\
\hline 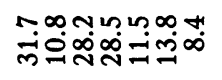 & : \\
\hline Hేmpong & $\stackrel{\Upsilon}{\Re}$ \\
\hline 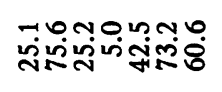 & $\stackrel{n}{+}$ \\
\hline 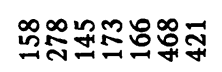 & 8 \\
\hline 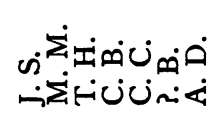 & 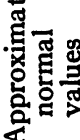 \\
\hline
\end{tabular}


TABLE III

Cerebral and other physiological data

\begin{tabular}{|c|c|c|c|c|c|c|c|c|c|c|c|c|}
\hline \multirow{3}{*}{ Patient } & \multicolumn{6}{|c|}{ Cerebral } & \multicolumn{3}{|c|}{ Respiratory } & \multirow[b]{2}{*}{$\begin{array}{c}\text { Mean } \\
\text { arterial } \\
\text { B. P. }\end{array}$} & \multirow[b]{2}{*}{$\begin{array}{c}\text { Pulse } \\
\text { rate } \\
\text { per min. }\end{array}$} & \multirow[b]{2}{*}{$\begin{array}{l}\text { Rectal } \\
\text { temp. } \\
{ }^{\circ} \mathrm{F} \text {. }\end{array}$} \\
\hline & Mental & $\begin{array}{c}\mathrm{A}-\mathrm{V} \\
\mathrm{O}_{2}\end{array}$ & $\mathrm{CBF}$ & $\underset{\mathrm{O}_{2}}{\mathrm{CMR}}$ & CVR & $\mathbf{R Q}$ & $\begin{array}{l}\text { Minute } \\
\text { volume }\end{array}$ & $\begin{array}{c}\text { Tidal } \\
\text { volume }\end{array}$ & $\begin{array}{c}\text { Rate } \\
\text { per } \\
\text { min. }\end{array}$ & & & \\
\hline & & vol. \% & $\begin{array}{l}\text { cc. } / 100 \\
\text { g. } / \min .\end{array}$ & $\begin{array}{l}c c . / 100 \\
\text { g./min. }\end{array}$ & $\frac{m m \cdot H g}{c c . / 100}$ & & liters & $c c$. & • & $m m . H g$ & & \\
\hline
\end{tabular}

Severe diabetic acidosis admission data

\begin{tabular}{l|l|l|l|l|l|l|l|l|l|l|r|r|r}
\hline J. S. & Confused & 9.9 & 41 & 4.1 & 1.8 & 0.84 & 7.5 & 500 & 15 & 74 & 130 & 95 \\
M. M. & Confused & 4.2 & 58 & 2.4 & 1.4 & 0.98 & 33 & 920 & 36 & 79 & 128 & 100 \\
M. G. & Confused & 4.7 & 55 & 2.6 & 1.1 & 0.87 & 35 & 880 & 40 & 58 & 120 & 102 \\
T. H. & Confused & 5.6 & 32 & 1.8 & 3.8 & 0.98 & 21 & 1100 & 19 & 120 & 110 & 99 \\
C. B. & Confused & 6.9 & 36 & 2.5 & 2.4 & 0.84 & 26 & 1300 & 20 & 86 & 116 & 100 \\
P. S. & Confused & 5.6 & 50 & 2.8 & 2.1 & 0.96 & 31 & 1200 & 25 & 107 & 94 & 99 \\
C. C. & Confused & 6.4 & 40 & 2.6 & 2.1 & 0.99 & 10.7 & 400 & 26 & 84 & 110 & 99 \\
A. B. & Confused & 6.9 & 44 & 3.0 & 1.8 & 0.88 & 16.9 & 770 & 22 & 80 & 110 & 98 \\
\hline Mean & & 6.3 & 45 & 2.7 & 2.1 & 0.92 & 23 & 880 & 25 & 86 & 115 & 99 \\
\hline
\end{tabular}

Diabetic coma admission data

\begin{tabular}{l|l|l|l|l|l|l|l|l|l|l|l|l}
\hline M. B. & Uncon. & 1.2 & 63 & 0.8 & 1.3 & 0.70 & & & & 80 & 160 & 96 \\
?. B & Uncon. & 4.3 & 35 & 1.5 & 1.8 & 0.98 & 28.4 & & & 64 & 120 & 96 \\
F. A. & Uncon. & 5.7 & 35 & 2.0 & 1.0 & 0.83 & 23.9 & & & 34 & 105 & 101 \\
A. D. & Uncon. & 2.4 & 80 & 1.9 & 0.8 & 0.96 & & & 65 & 110 & 98 \\
F. R. & Uncon. & 1.8 & 101 & 1.8 & 0.8 & 0.91 & 20 & 850 & 24 & 82 & 106 & 95 \\
M. O. & Uncon. & 2.8 & 78 & 2.1 & 0.9 & 0.81 & 25 & 780 & 32 & 72 & 135 & 97 \\
\hline Mean & & 3.0 & 65 & 1.7 & 1.1 & 0.87 & & & & 66 & 123 & 97 \\
\hline
\end{tabular}

Post treatment data

\begin{tabular}{l|l|l|l|l|l|l|l|l|l|l|r|r|r}
\hline J.S. & Alert & 4.9 & 63 & 3.1 & 1.4 & 1.25 & 7.7 & 550 & 14 & 90 & 112 & \\
M. M. & Alert & 5.8 & 54 & 3.1 & 1.1 & 0.93 & 18.7 & 750 & 25 & 62 & 112 \\
T. H. & Alert & 5.2 & 42 & 2.2 & 2.0 & 0.87 & 10 & 560 & 18 & 86 & 88 & 92 & 8 \\
C. B. & Alert & 8.1 & 40 & 3.2 & 2.3 & 0.90 & 5 & 560 & 9 & 84 & 100 \\
C. C. & Confused & 7.2 & 45 & 3.2 & 1.9 & 1.02 & 6.8 & 340 & 20 & 76 & \\
?. B. & Uncon. & 3.5 & 48 & 1.7 & 1.6 & 0.92 & 26.6 & & & 83 & \\
A. D. & Confused & 2.0 & 120 & 2.4 & 0.7 & 0.90 & & & & \\
\hline $\begin{array}{l}\text { Normal } \\
\text { values }\end{array}$ & & 6.3 & 54 & 3.3 & 1.6 & 0.99 & 8 & 500 & 16 & 86 & \\
\hline
\end{tabular}

[1 to 5]). The other type is characterized by unconsciousness, frequently associated with circulatory depression. These alone we have felt justified in classifying as diabetic coma. Satisfactory correction of the chemical disturbances in the blood of these patients has little effect on the course of the disease and the mortality is almost always high $(83 \%$ in our series, $80 \%$ in the four years preceding this investigation, $31 \%, 58 \%, 70 \%$, $73 \%, 75 \%$ and $81 \%$ in other series [1 to 6]). The overall mortality of any series of cases of diabetic acidosis and coma depends far more on the relative frequency of these two groups in the series than on the minor differences which may occur in a treatment so universally accepted and used. It should be pointed out that a diagnosis of coma on the basis of the plasma $\mathrm{CO}_{2}$ combining power, rather than on mental state, does not differentiate between these two groups and may be misleading from the point of view of prognosis and therapeutic results. A case in point is the overall mortality of $11 \%$ reported by one group (6) in a series of 525 cases of "diabetic coma" based on the plasma $\mathrm{CO}_{2}$, only $18 \%$ of whom were unconscious. The mortality in these 93 unconscious patients, however, was only $31 \%$, an enviable record in itself. It is worthy of note that all the deaths in our series were in patients 
who had never attended the Metabolic Clinic of the hospital, and in five of the six deaths the presence of diabetes had been unknown.

Acid-base balance. There was a marked reduction in the arterial carbon dioxide content, tension and $\mathrm{pH}$, a picture of uncompensated metabolic acidosis. The lowest value for $\mathrm{pH}$ (6.80) was obtained in a patient who subsequently recovered. There is surprisingly little difference between the "acidosis" and "coma" patients on the basis of these three functions. In all cases studied during or after treatment, which included moderate amounts of sodium bicarbonate, there was a striking recovery of $\mathrm{pH}$ to normal or nearly normal levels even though the plasma bicarbonate lagged far behind. The reason for this is seen in the slow return of the $\mathrm{CO}_{2}$ tension to normal indicative of only a gradual reduction of hyperventilation in response to the improved $\mathrm{pH}$. The practical implications of this with respect to the question of alkali administration are important. There is some controversy at present on the advisability, amount and route of administration of bicarbonate in the treatment of diabetic acidosis. Unfortunately the criterion of acidosis and response to treatment has been the plasma $\mathrm{CO}_{2}$ combining power, at best a very rough guide. Actually it is the ratio of bicarbonate to $\mathrm{CO}_{2}$ tension $\left(\mathrm{pCO}_{2}\right)$ which is important and this can best be determined by measurement of the $\mathrm{pH}$ which represents the resultant of all the blood buffer systems. Since the $\mathrm{pCO}_{2}$ does not rise pari passu with the administered bicarbonate the $\mathrm{pH}$ will be brought to normal much sooner than will the blood bicarbonate concentration. Thus, any attempt to administer alkali rapidly in quantities calculated to restore the $\mathrm{CO}_{2}$ combining power to a normal level can only result in a severe alkaline shift of the $\mathrm{pH}$ until the relatively sluggish respiratory adjustments are made. Our results demonstrate that it is possible to bring the arterial $\mathrm{pH}$ within normal limits quickly by means of the intravenous administration of amounts of bicarbonate small enough to raise the blood $\mathrm{CO}_{2}$ content only 10 or 15 vol. \%. For example, patients ? B., M. M. and C. C. showed a normal arterial $\mathrm{pH}$ with an alkali reserve less than half the normal after two to five hours of treatment. In the case of A. D. the arterial $\mathrm{pH}$ rose from 6.96 to 7.24 with a change in $\mathrm{BHCO}_{3}$ of from 5.1 to only $8.4 \mathrm{~m} . \mathrm{Eq} . / 1$. In pa- tient J. S. who was not severely acidotic, pulmonary ventilation was never above normal. He was therefore able to retain $\mathrm{CO}_{2}$, hence the $\mathrm{pH}$ and alkali reserve rose concomitantly. Similarly in patients T. H. and C. B., where sufficient time had elapsed between the two studies for adequate adjustment, both the $\mathrm{pH}$ and $\mathrm{BHCO}_{3}$ had been brought to normal values. It is clear that determination of arterial or, less exactly, venous $\mathrm{pH}$ constitutes a more reliable and accurate picture of the acidosis and, by techniques now available, a more conveniently estimated measure than the usual plasma $\mathrm{CO}_{2}$ combining power. With this safeguard, much of the objection which has been raised against the intravenous use of alkalies in the treatment of diabetic acidosis may be met. If it be conceded that acidosis in itself is not desirable there is little argument against the rapid correction of $\mathrm{pH}$ toward normal limits.

Arterial oxygen content and saturation. Many of these patients exhibited on admission higher values for arterial hemoglobin and oxygen content than is usual for hospital patients. This is most likely a reflection of associated dehydration and hemo-concentration. Even those patients whose admission values for blood hemoglobin concentration were not high were probably both dehydrated and anemic since determinations made after treatment invariably showed greater hemodilution. The figures for arterial oxygen saturation are approximations since oxygen capacity was not directly determined but was derived from the hemoglobin concentration and the factor 1.34 representing the oxygen capacity of one gram of hemoglobin. They indicate on the whole only a very slight reduction in arterial blood oxygen saturation (mean $=94 \%$ ) which, in view of the experimental errors, involved plus the generally severe acidosis which would be expected to depress the oxygen capacity of hemoglobin slightly, indicates the absence of significant interference with pulmonary gas exchange.

Pulmonary ventilation. The respiration was appreciably stimulated in practically all patients and, in many, was of the Küssmaul type. In an effort to ascertain the mechanisms possibly involved in this hyperpnea, the respiratory minute volume was tested for possible relationship with mean arterial blood pressure, arterial $\mathrm{CO}_{2}$ tension, $\mathrm{pH}$ and ketone concentration, and rectal temperature. 
There was little correlation except in the case of arterial $\mathrm{pH}$, a graph of which is shown in Figure 1. This includes some data on patients not otherwise studied. The relationship between pulmonary ventilation and $\mathrm{pH}$ is somewhat complex. There is evidence of a threshold at about $\mathrm{pH} 7.20$, respiration being relatively unaffected down to that point. Below $\mathrm{pH} 7.20$ respiratory volume rises sharply to a maximum of 35 liters $/ \mathrm{min}$. in the region of $\mathrm{pH} 7.0$. With increasing acidity the ventilation appears gradually to fall off. The initial threshold is similar to that of the carotid bodies to acidosis demonstrated by Comroe and Schmidt (21), and suggests that the mechanism for this hyperpnea may be a chemoreceptor reflex. That this stimulation should eventually give way to a depression as the acidosis increases in severity, possibly through depression of the medullary centers, is not unreasonable. It is interesting to note that in these patients, respiratory stimulation oc-

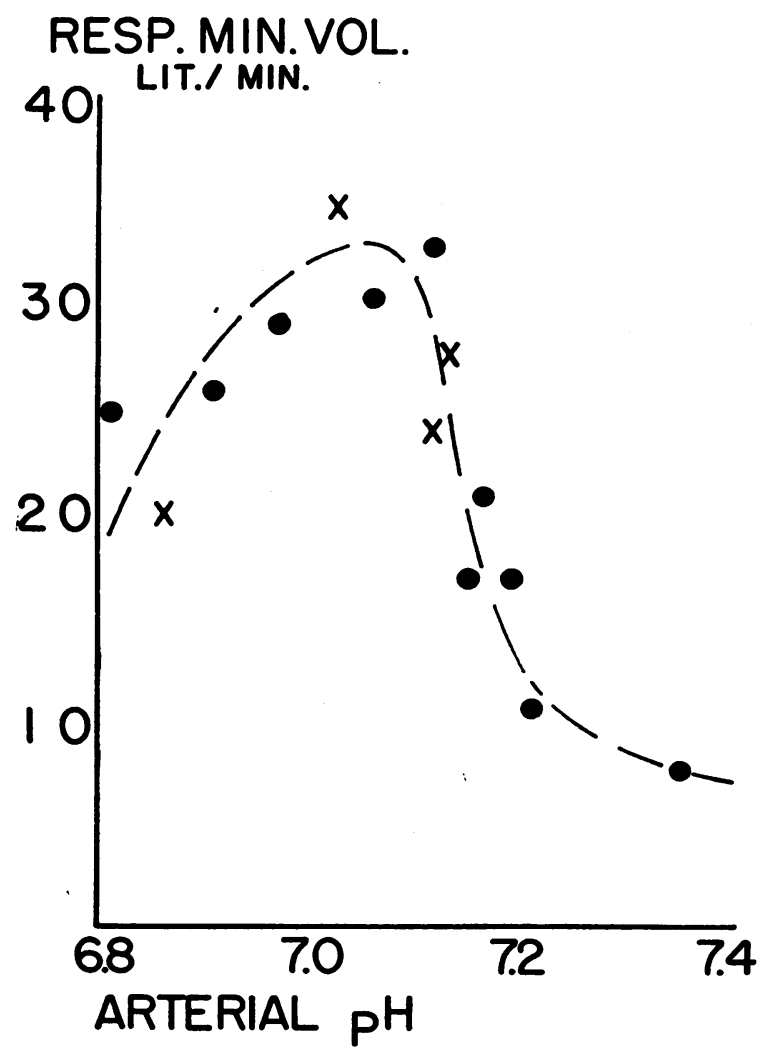

Fig. 1. The Relationship between Respiratory Minute Volume and Arterial pH

The circles represent patients who ultimately recovered, the crosses those who succumbed. curs in the face of a profound fall in arterial $\mathrm{CO}_{2}$ tension, indicating that at least in this condition the important regulatory function of carbon dioxide has been superseded by another agent, quite possibly hydrogen ion concentration. Our data for pulmonary ventilation and arterial $\mathrm{pH}$ after the acidosis has been corrected, although incomplete, suggest that the respiratory response lags considerably behind the response of $\mathrm{pH}$ to treatment, so that the hyperpnea may continue for a time after the arterial $\mathrm{pH}$ is close to normal. Should this observation be confirmed it would indicate either that the hydrogen ion is not the real factor concerned in the hyperpnea, or that some time must elapse before a change in the $\mathrm{pH}$ of arterial blood is reflected in the hydrogen ion concentration of the cells responsible for the respiratory stimulation.

Blood glucose and electrolytes. Values for blood glucose were elevated in all patients and indiscriminately with respect to the presence or absence of coma. This has also been the finding of others $(1,3,5)$. The mean values for plasma electrolytes are shown graphically in Figure 2 . Such studies have been made in some detail by others (22 to 24). These electrolyte patterns, in almost complete numerical agreement with those of Peters and associates (23), show a reduction in total base in diabetic acidosis, a considerable reduction in bicarbonate ion, and a progressive increase in the undetermined anion fraction (X) associated with, but by no means entirely explained by, an increase in total ketone bodies. These substances are abnormally elevated in the "acidosis" group and even more so in the patients with coma although the difference falls short of statistical significance. Thus, from the degree of acidosis, of hyperglycemia, of ketosis, and of disturbance in the blood electrolyte pattern there is little to explain the marked difference in mental state and prognosis between patients in diabetic coma and those with severe diabetic acidosis.

Mean arterial blood pressure. The average value for mean arterial blood pressure is definitely lower for the comatose patients $(66 \mathrm{~mm} . \mathrm{Hg})$ than the normal figure of $86 \mathrm{~mm}$. found in those who were acidotic but conscious, although this difference is short of statistical significance. This observation is explained by the well-established element of circulatory failure in diabetic coma most 


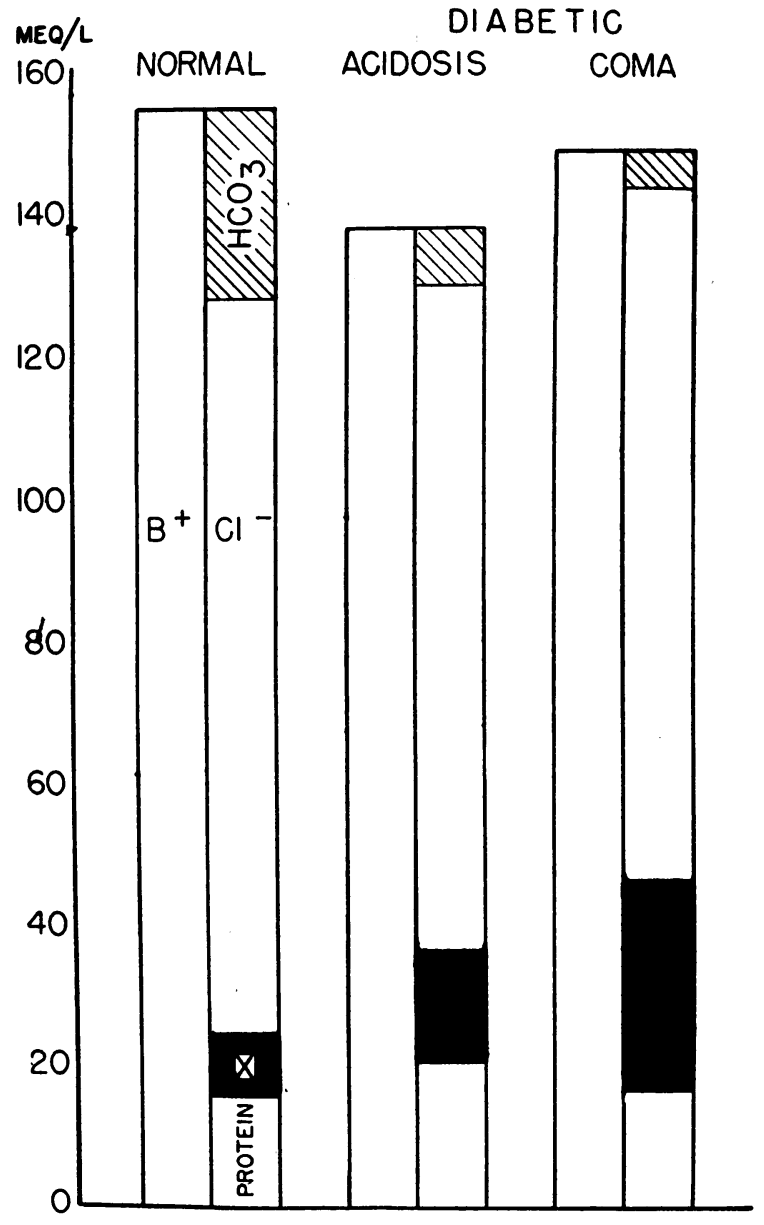

Fig. 2. The Blood Electrolyte Pattern in Diabetic Acidosis and Coma

The anion fraction $(\mathrm{X})$ represents phosphate, sulphate, and organic acids.

recently enunciated by Schecter, Wiesel and Cohn (25).

Cerebral blood flow and metabolism. In spite of the circulatory depression found in the comatose patients, only two showed a reduction in cerebral blood flow $(\mathrm{CBF})$. The others yielded figures for this function somewhat in excess of the normal and the mean value for the group was 65 as compared with a normal figure of $54 \mathrm{cc} . / 100 \mathrm{~g} . / \mathrm{min}$. (12). The patients with acidosis displayed a greater consistency in cerebral blood flow which was slightly reduced on the average $(45 \mathrm{cc} . / 100 \mathrm{~g}$./ min.). This difference between the two groups was largely due to a difference in tone of cerebral vessels, patients in coma showing a fairly consistent decrease in cerebrovascular resistance
(CVR) (1.1 resistance units) while this function was slightly increased in those patients in acidosis without coma (2.1 units). The normal value for cerebrovascular resistance is $1.6 \mathrm{~mm} . \mathrm{Hg} / \mathrm{cc}$./ $100 \mathrm{~g} . / \mathrm{min}$. (12).

Some explanation for the surprising observation of an actual increase in cerebral blood flow in diabetic coma is suggested if the blood flow be plotted against the $\mathrm{pH}$ of arterial blood (Figure $3)$. There is a fairly good correlation $(r=-0.70$, $p=0.01$ ) and the shape of the curve is similar to that found in normal subjects (26) where $\mathrm{pH}$ is altered by changing the $\mathrm{pCO}_{2}$ of the blood. In the case of the diabetic acidosis group, however, the curve is shifted to the left so that for comparable levels of $\mathrm{pH}$ the blood flow is lower in these patients than in normal subjects breathing 5-7\% carbon dioxide. This may be due to the fact that in the case of normal subjects breathing carbon dioxide both $\mathrm{pCO}_{2}$ and hydrogen ion concentration are increased and their individual effects are likely to be summated, while in diabetic acidosis the in-

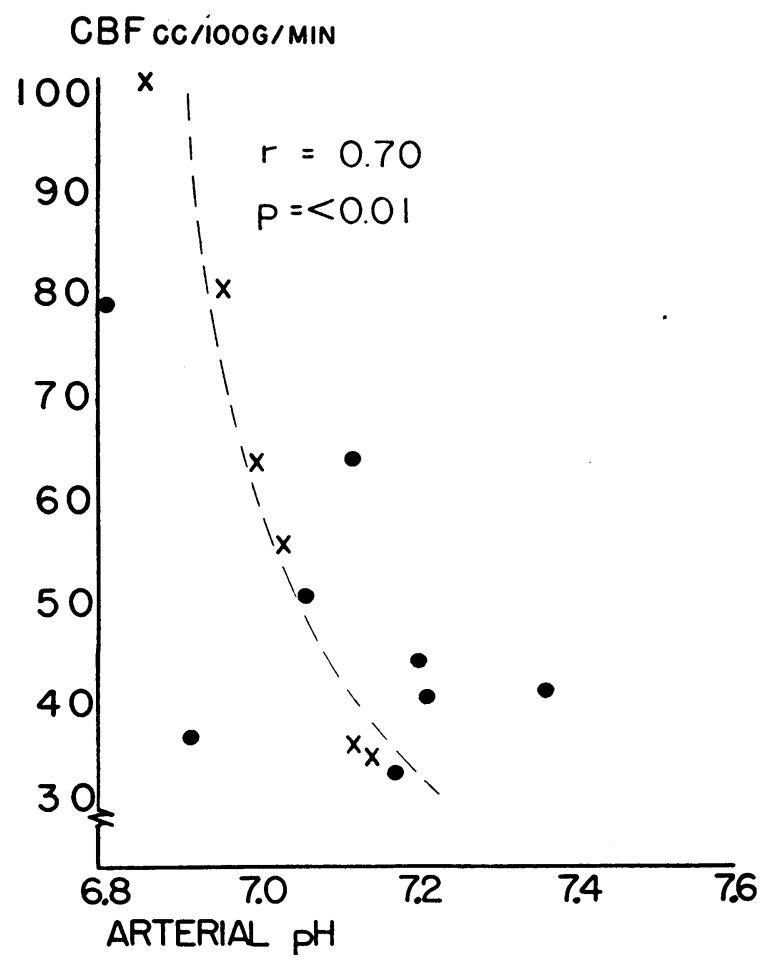

Fig. 3. The Relationship between Ceirebral Blood Flow and Arterial pH

The circles represent patients who ultimately recovered, the crosses those who succumbed. 
crease in hydrogen ion concentration occurs in the face of a marked fall in $\mathrm{pCO}_{2}$. It is not yet clear in the case of $\mathrm{CO}_{2}$ inhalation whether the cerebrovascular dilation is due to the $\mathrm{CO}_{2}$ itself or to the concomitant $\mathrm{pH}$ shift or to both; it is nevertheless evident that at least in the severe acidosis of diabetes, cerebral vessels may dilate even though the $\mathrm{CO}_{2}$ tension be remarkably low.

Of all the studies performed, measurement of cerebral metabolic rate in terms of oxygen consumed $\left(\mathrm{CMR}_{\mathrm{O}_{2}}\right)$ yielded by far the most significant difference between the comatose and noncomatose patients. As compared with a consumption of $3.3(\sigma= \pm 0.4)$ cc. of oxygen per $100 \mathrm{~g}$. of brain per minute found in mentally alert normal subjects (12), the comatose patients yielded an average of only $1.7(\sigma= \pm 0.4)$, a reduction of $48 \%$ and highly significant statistically. Those patients who were acidotic and confused but not unconscious on admission exhibited an average figure for cerebral $\mathrm{O}_{2}$ consumption of 2.7 ( $\sigma=$ \pm 0.4 ) cc. $/ 100 \mathrm{~g} . / \mathrm{min}$., moderately lower than the normal. In fact there seems to be a critical level for cerebral oxygen utilization of $2.1 \mathrm{cc}$./ $100 \mathrm{~g} . / \mathrm{min}$. at or below which consciousness disappears.

The cerebral respiratory quotient was consistently below unity, averaging 0.87 and 0.92 in the comatose and non-comatose groups, respectively. At the present state of our knowledge there is little justification for speculation on the basis for this slight but significant deviation from the normal of 0.99 (12).

It was hoped that by determination of cerebral arteriovenous glucose difference the utilization of this substance by the brain could be measured in this condition as has already been done in hypoglycemia (8). At the high blood sugar levels encountered, however, the arteriovenous difference was well within the error of the glucose determinations so that such an estimation is not possible until blood glucose methods of much higher precision are available.

\section{DISCUSSION}

It has been a discouraging finding repeatedly confirmed that the usual biochemical analyses in patients with severe diabetic acidosis fail to show any significant difference between those who are conscious, whose metabolic derangements are readily reversible by present therapy, and those who are in true coma with a grave prognosis, and a frequently. irreversible pattern of deterioration. The present studies indicate that cerebral oxygen utilization is at least one biochemical function which serves to differentiate these two groups. In all of the patients who were in coma on admission the cerebral oxygen consumption was 2.1 , cc. $/ 100 \mathrm{~g} . / \mathrm{min}$. or less while seven of the eight patients who still retained consciousness yielded a value for this function of $2.4 \mathrm{cc} . / 100 \mathrm{~g} . / \mathrm{min}$. or more. This measurement was also the only one of the many performed which had definite prognostic significance. With but one exception in each group, a cerebral oxygen consumption below 2.1 cc. $/ 100 \mathrm{~g} . / \mathrm{min}$. was incompatible with survival, whereas in those with values above that figure response to treatment was satisfactory and recovery took place. This depression in oxygen utilization is not limited to the brain. Schecter, Wiesel and Cohn have demonstrated a decrease in oxygen consumption in the extremities of patients in diabetic acidosis (25). In the brain, however, a defect in metabolism is of grave and immediate significance. The interesting correlation between mental state and utilization of oxygen by the brain is shown in Figure 4. The reduction in cerebral metabolism is accompanied by and undoubtedly

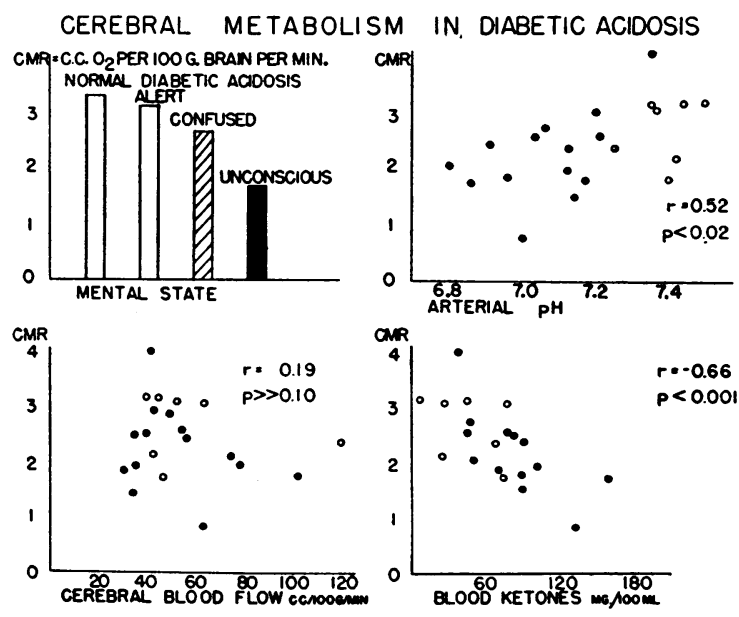

Fig. 4. Correlations of Cerebral Oxygen Consumption (CMR) with Mental State, Cerebral Blood Flow, Arterial pH and Arterial Ketone ConcenTRATION

The closed circles represent admission data, the open circles observations made in the course of therapy. 
responsible for the progressive deterioration of mental function which occurs in the course of uncorrected diabetic acidosis. We have observed a strikingly similar phenomenon in the hypoglycemia and coma induced by insulin ( 8 ), the stage of severe hypoglycemia and confusion being associated with a $\mathrm{CMR}_{\mathrm{O}_{2}}$ of 2.6 and the state of deep coma yielding an average of $1.9 \mathrm{cc} . \mathrm{O}_{2} / 100 \mathrm{~g}$./ min. Whereas in insulin hypoglycemia the depression of cerebral metabolism may reasonably be attributed to the profound drop in glucose available for utilization by the brain, it is by no means as easy to identify the process responsible for the decreased cerebral oxygen utilization in diabetic coma. There is evidence to indicate that insulin from the pancreas may be dispensable in the utilization of glucose by the brain (9), a very cogent observation being that in untreated human diabetics and depancreatized animals mental function is interfered with only late in the progress of the acidosis and other biochemical derangements. In a search for the possible factors directly responsible for this depressed utilization of oxygen by the brain, it may be pertinent to determine the correlation between $\mathrm{CMR}_{\mathrm{O}_{2}}$ and each of the biochemical and physiological disturbances known to occur in diabetic coma. On the basis of the circulatory failure usually found in this condition the reasonable thesis has been proposed that the coma is due to a deficiency in cerebral circulation (27). Our findings demonstrate that this is not so (Table III), and a correlation between $\mathrm{CMR}_{\mathrm{O}_{2}}$ and $\mathrm{CBF}$ (Figure 4) indicates that the cerebral oxygen utilization in this condition is almost completely unrelated to the cerebral blood flow. On the basis of this fact and the relatively normal arterial oxygen saturations observed, it may be concluded that the fault in cerebral oxygen utilization does not lie in the supply of oxygen to the brain. The possibility that the mechanisms for release of oxygen from the blood to cerebral tissue may be disturbed is now under investigation by a study of the oxyhemoglobin dissociation curve and the oxygen tensions in cerebral venous blood. With the reservation that a significant defect may be found there, it is probable that the fundamental derangement is in the cellular biochemical processes responsible for the normal utilization of oxygen. If these processes are at all dependent on the environmental $\mathrm{pH}$, and this can hardly be doubted, the acidosis itself might be expected to contribute to the depression in cerebral metabolism. There is a fair correlation (Figure 4) between $\mathrm{CMR}_{\mathrm{O}_{2}}$ and arterial $\mathrm{pH}$ which tends to justify this supposition. Of course the $\mathrm{pH}$ of arterial blood only indirectly affects the hydrogen ion concentration inside the cell and it is possible that this correlation would be considerably improved were the latter quantity measurable.

In 1914 Hurtley (28) suggested that acetoacetic acid was a noxious agent in diabetic acidosis and despite conflicting evidence (29), recent work has corroborated the toxic properties of this substance. Schneider and Droller (30) found that slow intravenous infusion of acetoacetic acid in rabbits regularly produced coma where even a greater acidosis resulting from administration of hydrochloric or beta hydroxybutyric acids had no such effect. In fact coma was consistently obtained even with sodium aceto-acetate where no acidosis accompanied the administration. Thus at least one of the ketone bodies is capable of producing coma although-the blood concentrations necessary are not known and may well be higher than those found in the coma of diabetic acidosis. Our own observations are compatible with the thesis that ketosis is an important factor contributing to this type of coma. Figure 4 shows a fairly good correlation between $\mathrm{CMR}_{\mathrm{O}_{2}}$ and blood ketone concentrations. Cerebral oxygen utilization fell as the blood ketone level rose. Such a correlation is open to a number of interpretations. It may mean that one or more of the ketone substances, acting as a histotoxic agent, is responsible for the depression in cerebral metabolism. An equally good possibility is that the blood ketone level is simply an index of less defined but more fundamental aberrations just as the blood urea concentration reflects, but is hardly responsible for, the disturbances in uremia. There is more to be said for the causal efficacy of the ketones, however, in that at least one of their number has been shown to be capable of producing coma in itself.

The results reported here are compatible with, but by no means demand, the following sequence of events. The glycosuria plus the loss of sodium from the body lead to the well-recognized but inadequately verified contraction in extracellular fluid space of which the blood volume is an im- 
portant component $(31,32)$. This can only result in a decrease in cardiac output compensated by a restriction in peripheral blood flow (25) and quite probably a marked decrease in renal blood flow. The work of McCance and Lawrence (33) as well as that of Peters, Kydd, Eisenman and Hald (23) stresses the importance of renal regulatory mechanisms in the excretion of keto-acids, while the experiments of Stadie, Zapp and Lukens (34) demonstrate the major role which peripheral tissues play in the utilization of ketone bodies. Thus this diversion of the decreased cardiac output from the kidneys and muscles, although necessary for the maintenance of blood flow through more immediately vital centers, sharply restricts the available mechanisms for the utilization and excretion of ketone bodies produced in this condition in excessive amounts (35). The important renal adjustment of the body hydrogen ion concentration is also disorganized (33). The resultant acidosis and ketosis, not to mention a number of poorly defined but possibly more important biochemical disturbances, produce serious derangements in cellular oxidations throughout the body. In the heart these derangements may lead to further circulatory failure, now on the basis of myocardial inefficiency in addition to the decreased blood volume. These disturbances in metabolism in the brain are probably responsible for the development of coma and eventual death.

The nature of the "irreversibility" of severe diabetic coma is somewhat indicated by the present studies but by no means clearly defined. It is one thing to establish a critical level of cerebral oxygen consumption below which death occurs in spite of therapy, but quite another to explain the nature of the process which cannot be reversed. One can only hope that further study will lead to a deeper insight into these processes for certainly the irreversible stage in this disease is relative only to our ability to comprehend and correct the biochemical and physiological aberrations which comprise it.

\section{SUM MARY}

1. Studies of blood gases, electrolytes, acid-base balance, respiration, blood pressure, cerebral blood flow and cerebral oxygen consumption are reported on 14 patients in severe diabetic acidosis, six of whom were in deep coma.
2. Respiratory minute volume in these patients was well correlated with arterial $\mathrm{pH}$.

3. Coma was associated with and probably the result of a $40 \%$ reduction in cerebral utilization of oxygen which occurred in spite of a generally augmented cerebral blood flow and a normal arterial oxygen saturation.

4. The depression in cerebral oxygen consumption is partly related to the acidosis and more significantly to the ketosis in this condition although other factors as yet poorly defined are undoubtedly operating.

5. The results establish the feasibility of applying these techniques in diabetic coma and open the possibility of further definition of the biochemical derangements in the living human brain by the study of more specific metabolic components.

\section{ACKNOWLEDGMENT}

The authors wish to acknowledge the cooperation of Doctors Edward S. Dillon and Anthony Sindoni, Jr., chiefs of service in the Metabolic Division; the splendid assistance of Miss Edith Erikson and the Metabolic nursing staff, and the painstaking analytical work of Misses Maxine Sortwell and Ruth Spear.

\section{BIBLIOGRAPHY}

1. Dillon, E. S., and Dyer, W. W., Factors influencing the prognosis in diabetic coma. Ann. Int. Med., 1937, 11, 602.

2. Baker, T. W., A clinical survey of 108 consecutive cases of diabetic coma. Arch. Int. Med., 1936, 58, 373.

3. Owens, L. B., and Rockwern, S. S., Prognosis in diabetic coma: basic importance of mental state. Am. J. M. Sc., 1939, 198, 252.

4. Rabinowitch, I. M., Fowler, A. F., and Bensley, E. H., Diabetic coma (an investigation of mortalities and reports of a severity index for comparative studies). Ann. Int. Med., 1939, 12, 1403.

5. Collen, M. F., Mortality in diabetic coma. Arch. Int. Med., 1942, 70, 347.

6. Joslin, E. P., Root, H. F., White, P., and Marble, A., Diabetic coma. J. A. M. A., 1942, 119, 1160.

7. Mulder, A. G., and Crandall, L. A., Cerebral metabolism in fat fed dogs. Am. J. Physiol., 1942, 137, 436.

8. Kety, S. S., Woodford, R. B., Harmel, M. H., Freyhan, F. A., Appel, K. E., and Schmidt, C. F., Cerebral blood flow and metabolism in schizophrenia. The effects of barbiturate semi-narcosis, insulin coma and electroshock. Am. J. Psychiat., 1948 , In press. 
9. Himwich, H. E., and Nahum, L. H., The respiratory quotient of the brain. Am. J. Physiol., 1932, 101, 446.

10. Soskin, S., and Levine, R., Carbohydrate Metabolism. University of Chicago Press, Chicago, 1946.

11. Kety, S. S., and Schmidt, C. F., The determination of cerebral blood flow in man by the use of nitrous oxide in low concentrations. Am. J. Physiol., 1945, 143, 53.

12. Kety, S. S., and Schmidt, C. F., The nitrous oxide method for the quantitative determination of cerebral blood flow in man; theory, procedure and normal values. J. Clin. Invest., 1948, 27, 476.

13. Peters, J. A., and Van Slyke, D. D., Quantitative Clinical Chemistry. Williams \& Wilkins, Baltimore, 1931.

14. Evelyn, K. A., and Malloy, H. T., Microdetermination of oxyhemoglobin, methemoglobin, and sulfhemoglobin in a single sample of blood. J. Biol. Chem., 1938, 126, 655.

15. Polis, B. D., and Sortwell, M., Rapid photocolorimetric micro procedure for blood sugar using copper reduction with perchloric acid deproteinized filtrates. Arch. Biochem., 1946, 11, 229.

16. Greenberg, L. A., and Lester, D., A micromethod for the determination of acetone and ketone bodies. J. Biol. Chem., 1944, 154, 177.

17. Kingsley, G. R., The determination of serum total protein, albumin, and globulin by the biuret reaction. J. Biol. Chem., 1939, 131, 197.

18. Sendroy, J., Jr., Microdetermination of chloride in biological fluids, with solid silver iodate. III. Colorimetric analysis. J. Biol. Chem., 1937, 120, 419.

19. Polis, B. D., and Reinhold, J. G., The determination of total base of serum by ion exchange reactions of synthetic resins. J. Biol. Chem., 1944, 156, 231.

20. Karr, W. G., A method for the determination of blood urea nitrogen. J. Lab. \& Clin. Med., 1924, 9, 329.

21. Comroe, J. H., Jr., and Schmidt, C. F., The part played by reflexes from the carotid body in the chemical regulation of respiration in the dog. Am. J. Physiol., 1938, 121, 75.

22. Atchley, D. W., Loeb, R. F., Richards, D. W., Jr., Benedict, E. M., and Driscoll, M. E., On diabetic acidosis; a detailed study of electrolyte balances following the withdrawal and reestablishment of insulin therapy. J. Clin. Invest., 1933, 12, 297.

23. Peters, J. P., Kydd, D. M., Eisenman, A. J., and Hald, P. M., The nature of diabetic acidosis. J. Clin. Invest., 1933, 12, 377.

24. Hartmann, A. F., and Darrow, D. C., Chemical changes occurring in the body as the result of certain diseases. III. The composition of the plasma in severe diabetic acidosis and the changes taking place during recovery. J. Clin. Invest., 1928, 6, 257.

25. Schecter, A. E., Wiesel, B. H., and Cohn, C., Peripheral circulatory failure in diabetic acidosis and its relation to treatment. Am. J. M. Sc., 1941, 202, 364.

26. Kety, S. S., and Schmidt, C. F., Effects of altered arterial tensions of carbon dioxide and oxygen on cerebral blood flow and cerebral oxygen consumption of normal young men. J. Clin. Invest., 1948, $27,484$.

27. Dillon, E. S., Riggs, H. E., and Dyer, W. W., Cerebral lesions in uncomplicated fatal diabetic acidosis. Am. J. M. Sc., 1936, 192, 360.

28. Hurtley, W. H., The four carbon atom acids of diabetic urine. Quart. J. Med., 1915, 9, 301.

29. Dodds, E. C., and Robertson, J. D., The relation of aceto-acetic acid to diabetic coma and the cause of death. Lancet, 1930, 218, 852.

30. Schneider, R., and Droller, H., Relative importance of ketosis and acidosis in production of diabetic coma. Quart. J. Exper. Physiol., 1938, 28, 323.

31. Chang, H. C., Harrop, G. A., Jr., and Schaub, B. M., The circulating blood volume in diabetic acidosis. J. Clin. Invest., 1928, 5, 407.

32. Jacobson, S. D., and Lyons, R. H., The changes in the blood volume produced by diabetic acidosis. J. Lab. \& Clin. Med., 1942, 27, 1169.

33. McCance, R. A., and Lawrence, R. D., The secretion of urine in diabetic coma. Quart. J. Med., 1935, 4, 53.

34. Stadie, W. C., Zapp, J. A., Jr., and Lukens, F. D. W., Effect of insulin upon ketone metabolism of normal and diabetic cats. J. Biol. Chem., 1940, 132, 423.

35. Stadie, W. C., Fat metabolism in diabetes mellitus. J. Clin. Invest., 1940, 19, 843. 